\title{
The Effect of Neoadjuvant Chemotherapy on ER, PR and HER-2 Expression in Breast Cancer
}

\author{
Zheng Nie \\ Breast Surgery, The First People's Hospital of Jingzhou City, Jingzhou, China \\ Email: 317141884@qq.com
}

How to cite this paper: Nie, Z. (2019) The Effect of Neoadjuvant Chemotherapy on ER, PR and HER-2 Expression in Breast Cancer. Yangtze Medicine, 3, 163-175. https://doi.org/10.4236/ym.2019.33017

Received: January 9, 2019

Accepted: June 25, 2019

Published: June 28, 2019

Copyright $\odot 2019$ by author(s) and Scientific Research Publishing Inc. This work is licensed under the Creative Commons Attribution International License (CC BY 4.0).

http://creativecommons.org/licenses/by/4.0/ (c) (i) Open Access

\begin{abstract}
Objective: Through comparativing the change of the ER, PR and HER-2 expression in tumor tissue before and after neoadjuvant chemotherapy (NAC) in locally advanced breast cancer patient, to discuss whether there is influence for NACon ER, PR, HER-2 expression for breast cancer. Also, the relationship of ER, PR, HER-2 and chemosensitivity is also discussed. Methods: The expressions of ER, PR and HER2 in paraffin sections of breast cancer tissues from 51 patients before and after NAC were detected by immunohistochemical method. The assessment for the relationships between ER, PR, HER-2 and the efficiently of NAC is done. Results: For the 51 peoples, there is no statistical significance for change of ER, PR and HER-2 expression before and after NAC $(P>0.05)$. There is statistical significance for the differences of chemotherapeutic effectiverate between ER negative and ER positive, PR negative and PR positive, HER2 over-expressed group and HER2 non over-expressed group $(\mathrm{P}<0.05)$. Pathological complete response $(\mathrm{pCR})$ was related to molecular classification and the number of chemotherapy cycles. There is statistically significant or prognisis difference about hormone receptor, HER2 over-expressed and three-negative breast cancer $(\mathrm{P}<0.05)$. Conclusion: NAC maybe could not change the expression of ER and PR, and HER2 for breast cancer patients. The patients with HER-2 over-expressed are not sensitive to chemotherapy, and the patients with ER or PR negative get more benefits from chemotherapy. The breast cancer patients who could obtain pCR could get better prognosis after NAC.
\end{abstract}

\section{Keywords}

Breastcancer, Neoadjuvant Chemotherapy, ER, PR, HER-2

\section{Introduction}

Breast cancer is a malignant tumor with a high incidence, accounting for $7 \%$ - 
$10 \%$ of patients with malignant tumors [1]. Breast cancer is the second most common malignant tumor in women. According to the statistics, the quality of breast cancer patients in China has accounted for $12.2 \%$ of worldwide breast cancer patients. The number of infected people can reach more than 160,000 per year and it is the second common malignant tumor for women, the deaths can reach more than 40,000, accounting for $9.6 \%$ in the world [2]. It is the sixth leading cause of death common malignant tumors among women, and its incidence is still increasing year by year. It is estimated that by 2030, the number of persons infected breast cancer will reach 2.64 million cases worldwide and the death toll will be reached 1.7 million [3]. The pathological features, biological characteristics and prognosis of breast cancer are closely related to the expression of ER、PR and HER-2 in system. Although surgical treatment is still the first choice for the treatment of breast cancer, the importance of adjuvant chemotherapy is getting more and more attention.

Neoadjuvant Chemotherapy (NAC) refers to use of systemic cytotoxic drugs for person who is already diagnosed malignancy before surgery or before radiotherapy. Neoadjuvant chemotherapy has been clinically carried out since the 1970 s and it is an important treatment. Although NAC does not improve disease-free survival (DFS) and overall survival (OS), it can significantly increase the chance of surgery in patients with locally advanced breast cancer [4]. NAC is a clinically widely used trend. For patients with locally advanced breast cancer, it is generally the preferred treatment.

In this experiment, we examined the expression of ER, PR and HER2 in tumor tissues before and after neoadjuvant chemotherapy in 51 patients with locally advanced breast cancer, and compared them to understand the effect of NAC on these factors and the efficacy of neoadjuvant chemotherapy. And the survival of different types of breast cancer patients was evaluated.

\section{Data Collection}

\subsection{Experimental Object}

51 patients who were diagnosed (In core needle penetration pathology department) as breast cancer and received neoadjuvant chemotherapy by the First People's Hospital of Jingzhou City from 2010 to 2013. All selected person are women (Age: 28 - 65 years old). Median age is 48.8 years old, no other treatment was done before neoadjuvant chemotherapy. All patients have completed the entire treatment plan, tumor diameter $\geq 4 \mathrm{~cm}$ (measured by clinical physical examination two-path measurement combined with color Doppler ultrasound measurements to obtain primary breast cancer Size values), all patients had no distant metastasis.

\subsection{Neoadjuvant Chemotherapy}

The chemotherapy cycle of all cases is 2 cycles at least, the anthracycline combined with purple shirts mainly are mainly used. Chemotherapy regimens in- 
cludes TEC, EC-T, FEC-T, and NP regimens, as follows: TEC regimen: DOC (Docetaxel) $75 \mathrm{mg} / \mathrm{m}^{2}$, EPI (Epirubicin) $100 \mathrm{mg} / \mathrm{m}^{2}$, CTX (Cyclophosphamide) $500 \mathrm{mg} / \mathrm{m}^{2} \mathrm{~d}_{1}$. EC-Tregimen: EPI $100 \mathrm{mg} / \mathrm{m}^{2}$, CTX $600 \mathrm{mg} / \mathrm{m}^{2} \mathrm{~d}_{1}$, sequential administration of DOC $100 \mathrm{mg} / \mathrm{m}^{2} \mathrm{~d}_{1}$ after 4 cycles. FEC-Tprotocol: 5-FU500 $\mathrm{mg} / \mathrm{m}^{2}$, EPI $100 \mathrm{mg} / \mathrm{m}^{2}$, DOC $100 \mathrm{mg} / \mathrm{m}^{2} \mathrm{~d}_{1}$, sequential administration of DOC $100 \mathrm{mg} / \mathrm{m}^{2} \mathrm{~d}_{1}$ after 3 cycles. NP regimen: NVB (Vinorelbine) $25 \mathrm{mg} / \mathrm{m}^{2} \mathrm{~d}_{1}, \mathrm{~d}_{8}$, DDP (Cis-platinum complexes) $75 \mathrm{mg} / \mathrm{m}^{2} \mathrm{~d}_{1}$, all are 3 week plan. Before the next cycle of chemotherapy, the changes in tumor size were assessed by measurement and mammography to assess the efficacy of chemotherapy. In the third cycle, patients who were evaluated as ineffective before chemotherapy were changed to their chemotherapy regimen to re-enter the evaluation procedure or to change the treatment plan for surgery.

\subsection{Experimental Methods}

Immunohistochemistry was used to detect ER, PR and HER-2 in breast cancer tissues before and after neoadjuvant chemotherapy.ER, PR and HER2 antibodies were purchased from Ventana, USA. The film was read by a professional pathology chief physician through an optical microscope, and the results were judged based on the percentage of positive cells. According to the results of HE staining, the tumor tissue is distinguished from the normal breast tissue, and the cancer nest is distinguished from the cancerous periphery. The evaluation criteria for ER and PR: 1) $\geq 50 \%$ of infiltrating cancer cells were labeled with nuclear staining (+++); 2) $20 \%-50 \%$ of infiltrating cancer cells were labeled with nuclear staining $(++)$; 3) $1 \%-20 \%$ of invasive cancer cells are labeled with nuclear staining (+); 4) labeled negative if not stained. The recommended criteria "Herceptin Test" was used for determining HER-2 results.ER, PR, and HER2 are changed from +++ to,--++++ to +-- , and + to - are determined to be down-regulated. Otherwise, it shall be determined to up-regulated.

\subsection{Efficacy Evaluation}

The efficacy of chemotherapy was measured by the change of the size of the primary breast cancer. The size of the primary breast cancer was measured by clinical examination and combined with the color ultrasound measurement. According to the solid tumor efficacy evaluation criteria established by "WHO", the efficacy of breast cancer chemotherapy was evaluated.

\subsection{Follow-Up Visit}

From the start of treatment to March 31, 2016, the median follow-up time was 45 months. All patients were followed up by telephone or outpatient visit and the DFS and OS data were obtained.

\section{Statistical Methods}

All data were processed by statistical software SPSS19.0. The correlation between 
ER, PR and HER2 and neoadjuvant chemotherapy and their changes before and after neoadjuvant chemotherapy were inspected by the calibration $\mathrm{X}^{2}$ and use Kaplan-Meier to analyze the survival of breast cancer. $\mathrm{P}<0.05$ was considered statistically significant.

\section{Results}

\subsection{More Information about Sociodemographic and Clinical Characteristics of the Participants Should Be Showed in Table 1}

See Table 1.

Table 1. Sociodemographic and clinical characteristics of the participants $(n=51)$.

\begin{tabular}{|c|c|c|}
\hline \multicolumn{2}{|c|}{ Clinical characteristics } & \multirow{2}{*}{$\begin{array}{c}\mathrm{n} \\
25\end{array}$} \\
\hline & $\geq 50$ & \\
\hline Age (years) & $<50$ & 26 \\
\hline \multirow{2}{*}{ Menopausal } & No & 22 \\
\hline & Yes & 29 \\
\hline \multirow{3}{*}{ Paracentesis type } & Invasive duct carcinoma & 38 \\
\hline & Invasive small-leaf cancer & 3 \\
\hline & Myeloid cancer & 1 \\
\hline \multirow{4}{*}{ TNM periodization } & IIb & 14 \\
\hline & IIIa & 32 \\
\hline & IIIb & 4 \\
\hline & IIIc & 1 \\
\hline \multirow{4}{*}{ ER } & - & 16 \\
\hline & + & 7 \\
\hline & ++ & 8 \\
\hline & +++ & 20 \\
\hline \multirow{4}{*}{$\mathrm{PR}$} & - & 20 \\
\hline & + & 15 \\
\hline & ++ & 19 \\
\hline & +++ & 7 \\
\hline \multirow{4}{*}{ HER-2 } & 0 & 23 \\
\hline & + & 8 \\
\hline & ++ & 10 \\
\hline & +++ & 10 \\
\hline \multirow{4}{*}{ Chemotherapy programme } & $\mathrm{EC}$ & 41 \\
\hline & EC-T & 4 \\
\hline & TEC & 4 \\
\hline & NP & 2 \\
\hline \multirow{2}{*}{ Preoperative chemotherapy } & $\leq 3$ & 23 \\
\hline & $>3$ & 28 \\
\hline \multirow{3}{*}{ Molecular typing of breast cancer } & Luminal subtype & 34 \\
\hline & Her-2 over-expression subtype & 9 \\
\hline & Triple Negative subtype & 8 \\
\hline
\end{tabular}




\subsection{Relationship between Expression of ER, PR, HER2 and Curative Effect of Chemotherapy}

Clinical assessment of curative effect after 2 - 6 cycles of neoadjuvant chemotherapy: 15 patients with $\mathrm{PR}$ (partial response), 17 patients with CR (complete remission), 9 patients with SD (stable disease), and 1 patient with disease progression, with a total effective rate of $80.3 \%$. The pCR (pathologic complete response) was 9 cases. Statistical analysis showed that the difference in the effective rate between the negative and positive groups of ER, PR, HER2 was statistically significant $(\mathrm{P}<0.05), \mathrm{ER}, \mathrm{PR}$ and HER2 negative breast cancer were more sensitive to neoadjuvant chemotherapy (details should be showed in Table 2).

\subsection{Analysis of Influencing Factors of Pathological Complete Response Rate}

Among the 51 patients, breast cancer patients with positive hormone receptors had lower pCR rates. Age, menstrual status, pathological type of tumor, clinical stage, hormone receptor status, HER2 expression status, and chemotherapy regimen were not significantly associated with neoadjuvant chemotherapy for pathological complete remission $(\mathrm{P}>0.05)$, while the number of neoadjuvant chemotherapy cycles and the molecular typing status was significantly correlated with pathological complete remission $(\mathrm{P}<0.05)$ (details should be showed in Table 3 ).

\subsection{Changes in Tumor Biological Factors before and after Neoadjuvant Chemotherapy}

Among the 51 patients, 9 patients have achieved pathological remission, and no cancer tissue was detected after chemotherapy. In the other 42 cases with cancer tissue detection, ER, PR, and HER-2 showed some changes after chemotherapy. However, these changes were not statistically significant $(\mathrm{p}>0.05)$ (details should be showed in Table 4 and Figure 1).

\subsection{Influence Factors for Survival Prognosis}

The follow-up time of all cases was from 12 months to 55 months. The median follow-up time was 45 months. The DFS and OS for hormone receptor type were

Table 2. The relationship between the changes of ER, PR, HER2 and the efficacy of NAC $(\mathrm{n}=51)$.

\begin{tabular}{ccccccc}
\hline & & $\mathrm{pCR}$ & $\mathrm{CR}+\mathrm{PR}$ & $\mathrm{SD}+\mathrm{PD}$ & $\mathrm{x}^{2}$ & $\mathrm{P}$ \\
\hline \multirow{2}{*}{$\mathrm{ER}$} & - & 6 & 22 & 2 & 7.753 & 0.021 \\
& + & 3 & 10 & 8 & & \\
PR & - & 7 & 11 & 3 & & \\
& + & 2 & 21 & 7 & 6.105 & 0.047 \\
\multirow{2}{*}{ HER2 } & +++ & 1 & 9 & 7 & & \\
\multirow{2}{*}{ Total } & Ohter & 8 & 23 & 3 & 8.441 & 0.015 \\
\hline
\end{tabular}


Table 3. The correlation for pathological complete response and each factor $(n=51)$.

\begin{tabular}{|c|c|c|c|c|c|}
\hline \multirow{2}{*}{$\mathrm{P}$} & \multicolumn{2}{|c|}{ pCR } & \multicolumn{2}{|c|}{ non-pCR } & \multirow{2}{*}{$\mathrm{P}$} \\
\hline & $\mathrm{n}$ & Percentage & $\mathrm{n}$ & Percentage & \\
\hline \multicolumn{6}{|l|}{ Age (years) } \\
\hline$\geq 50$ & 5 & 9.8 & 20 & 39.1 & \multirow{2}{*}{0.187} \\
\hline$<50$ & 4 & 7.8 & 22 & 43.1 & \\
\hline \multicolumn{6}{|l|}{ Menopausa } \\
\hline No & 3 & 5.9 & 19 & 37.3 & \multirow{2}{*}{0.420} \\
\hline Yes & 6 & 11.8 & 23 & 45.1 & \\
\hline \multicolumn{6}{|l|}{ Paracentesis type } \\
\hline Invasiveduct carcinoma & 8 & 15.8 & 30 & 58.8 & \multirow{3}{*}{0.736} \\
\hline Invasive small-leaf cancer & 0 & 0 & 2 & 3.9 & \\
\hline Myeloid cancer & 1 & 1.9 & 0 & 0 & \\
\hline \multicolumn{6}{|l|}{ TNM periodization } \\
\hline $\mathrm{IIb}$ & 2 & 3.9 & 12 & 23.5 & \multirow{4}{*}{0.834} \\
\hline IIIa & 7 & 13.7 & 25 & 49 & \\
\hline IIIb & 0 & 0 & 3 & 5.9 & \\
\hline IIIc & 0 & 0 & 1 & 1.9 & \\
\hline \multicolumn{6}{|l|}{ ER } \\
\hline Negative & 6 & 11.8 & 10 & 19.6 & \multirow{2}{*}{0.920} \\
\hline Positive & 3 & 5.9 & 31 & 60.8 & \\
\hline \multicolumn{6}{|l|}{ PR } \\
\hline Negative & 7 & 13.7 & 13 & 25.5 & \multirow{2}{*}{0.818} \\
\hline Positive & 2 & 3.9 & 29 & 56.9 & \\
\hline \multicolumn{6}{|l|}{ Her-2 } \\
\hline Negative & 8 & 15.7 & 33 & 64.7 & \multirow{2}{*}{0.501} \\
\hline Positive & 1 & 2 & 9 & 17.6 & \\
\hline \multicolumn{6}{|l|}{ Chemotherapy programme } \\
\hline TEC & 9 & 17.6 & 32 & 62.2 & \multirow{4}{*}{0.666} \\
\hline EC-T & 0 & 0 & 4 & 7.8 & \\
\hline FEC-T & 0 & 0 & 4 & 7.8 & \\
\hline NP & 0 & 0 & 2 & 3.9 & \\
\hline \multicolumn{6}{|l|}{ Preoperative chemotherap } \\
\hline$\leq 3$ & 4 & 5.9 & 19 & 54.9 & \multirow{2}{*}{0.002} \\
\hline$>3$ & 5 & 11.8 & 23 & 27.5 & \\
\hline \multicolumn{6}{|l|}{ Molecular typing } \\
\hline Luminal subtype & 2 & 3.9 & 32 & 62.2 & \\
\hline Her2 over-expression & 4 & 7.8 & 5 & 9.8 & 0.007 \\
\hline Triple Negative subtype & 5 & 5.8 & 5 & 9.8 & \\
\hline
\end{tabular}




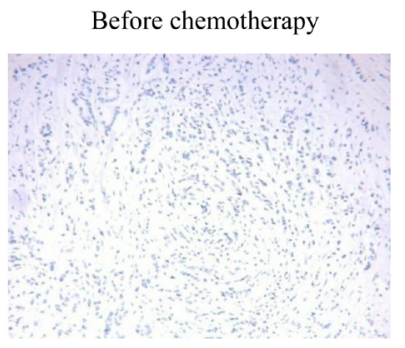

$\operatorname{ER}(-)$

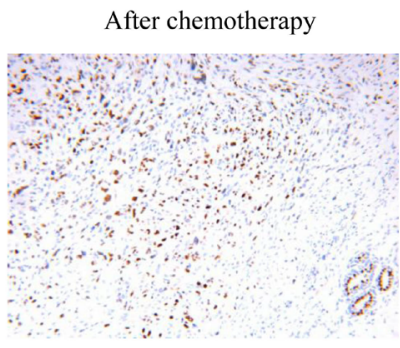

ER $(++)$

(a)

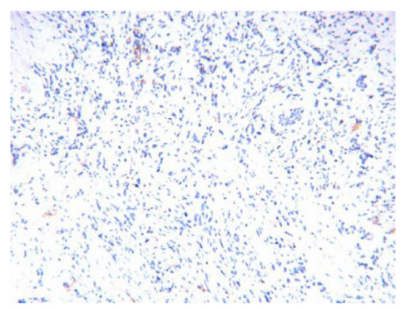

PR (-)

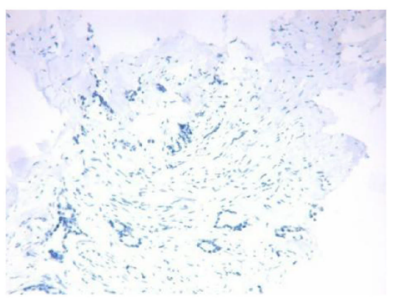

HER2 (0)

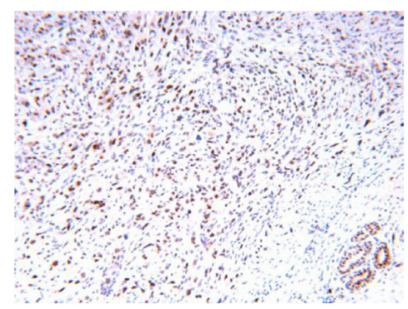

PR $(++)$

(b)

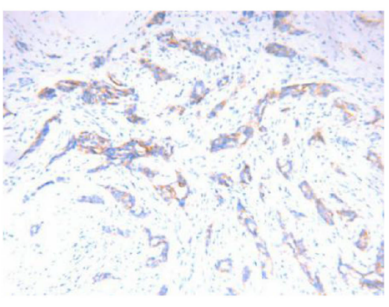

HER2 (2+)

(c)

Figure 1. (a): The ER expression change before and after NAC $(\times 200)$; (b): The PR expression change before and after NAC $(\times 200)$; (c): The HER-2 expression change before and after NAC $(\times 200)$.

Table 4. The compare about ER, PR, HER2 change before and after neoadjuvant chemotherapy.

\begin{tabular}{|c|c|c|c|c|c|c|}
\hline & \multicolumn{2}{|c|}{ ER } & \multicolumn{2}{|c|}{$\mathrm{PR}$} & \multicolumn{2}{|c|}{ Her2 } \\
\hline & $(-)$ & $(+)$ & $(-)$ & $(+)$ & $(-)$ & $(+)$ \\
\hline Before chenotherapy & 11 & 31 & 12 & 30 & 31 & 11 \\
\hline After chemotherapy & 13 & 29 & 13 & 29 & 28 & 14 \\
\hline $\mathrm{x} 2$ & 0.2 & 33 & 0.0 & 57 & 0.5 & 13 \\
\hline $\mathrm{P}$ & 0.6 & 29 & 0.8 & 11 & 0.4 & 74 \\
\hline
\end{tabular}

significantly higher than HER-2 type and triple negative type $(\mathrm{P}<0.05)$. There is statistic significance (see Figure 2 and Figure 3 about details). The DFS of the pCR and non-pCR groups were $88.9 \%$ and $47.6 \%$, respectively, $\mathrm{P}=0.005$; the OS of the pCR and non-pCR groups were $100 \%$ and $71.4 \%$, respectively, $\mathrm{P}=0.041$. After neoadjuvant chemotherapy, the breast cancer patient who has received pCR had significantly longer DFS and OS than patients who did not receive pCR (see Figure 4 and Figure 5). 


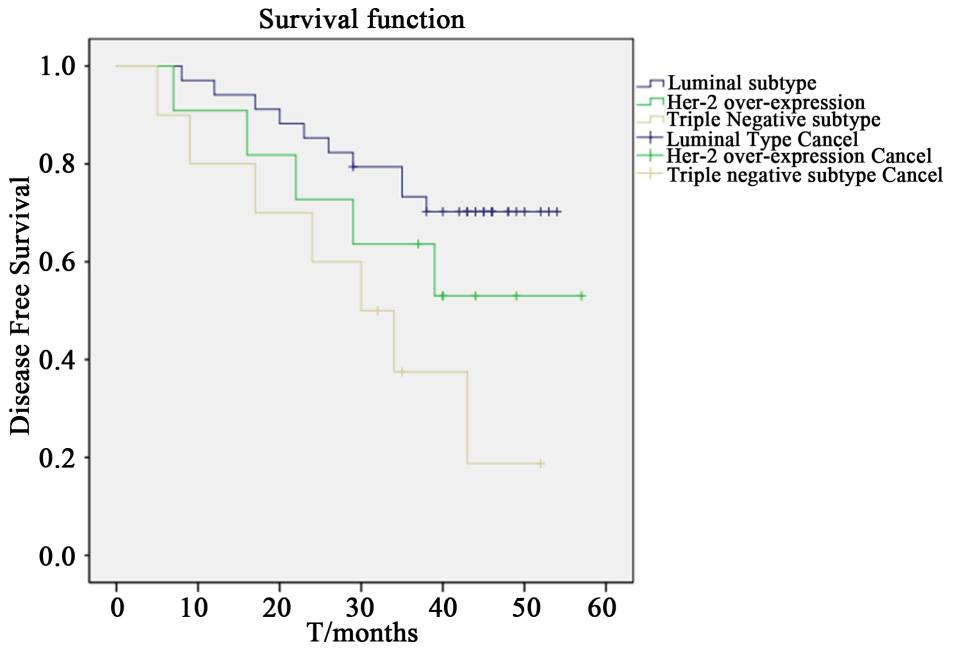

Figure 2. The Kaplan-Meier analysis for disease free survival about different molecular subtype of breast cancer $(\mathrm{P}=0.02)$.

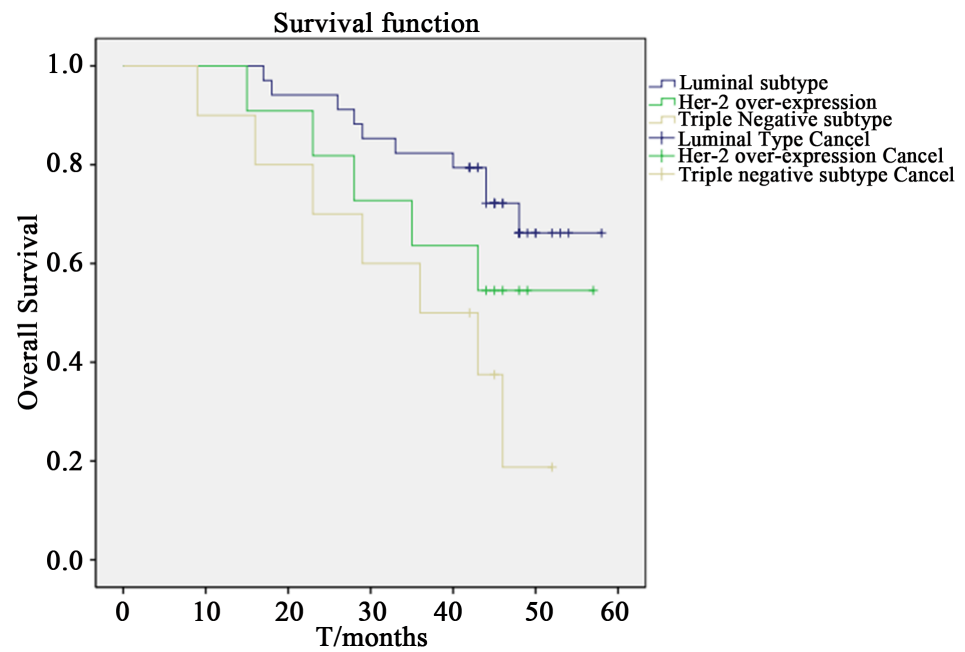

Figure 3. The Kaplan-Meier analysis for overall survival about different molecular subtype of breast cancer $(\mathrm{P}=0.03)$.

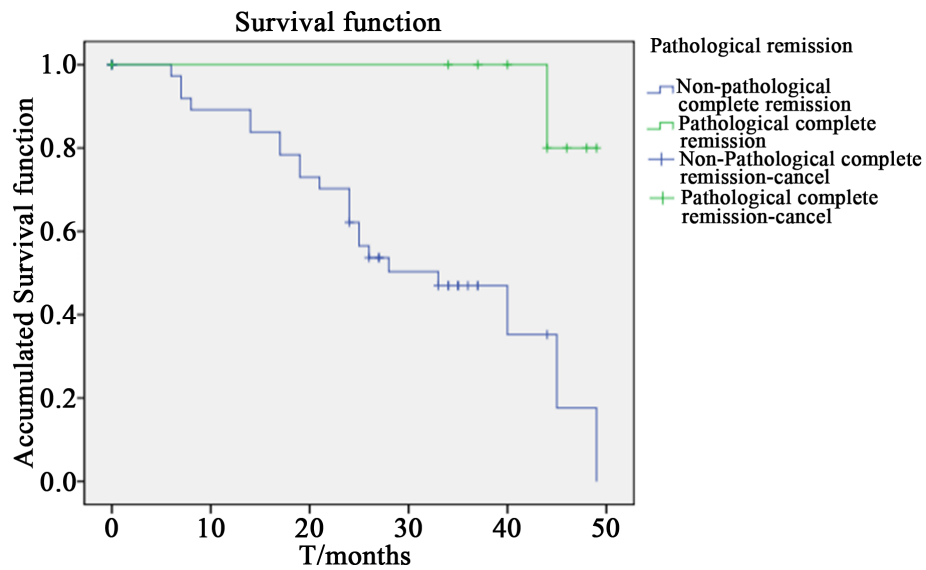

Figure 4. The Kaplan-Meier analysis for disease free survival about pCR and non-pCR of breast cancer $(\mathrm{P}=0.005)$. 


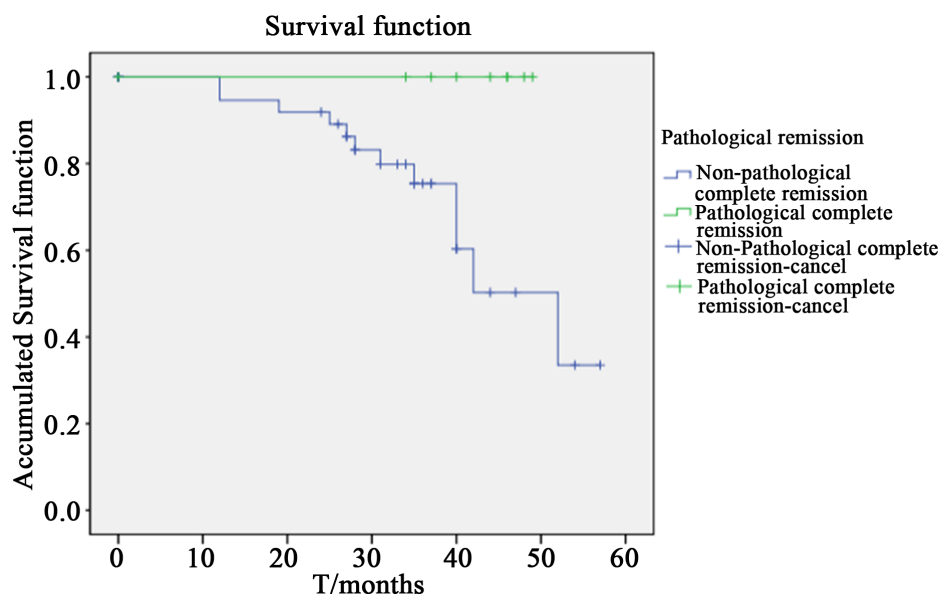

Figure 5. The Kaplan-Meier analysis for overall survival about pCR and non-pCR of breast cancer $(\mathrm{P}=0.041)$.

\section{Discussion}

Neo-adjuvant chemotherapy (NAC) can reduce tumor burden, reduce tumor volume, reduce tumor stage, increase patient's chance of surgery, and increase breast-conserving rate by eliminating tumor cells. At the same time, we could also obtain information on the response of the tumor to the treatment through tumor size change and pathological change, it will be a great help for developing a treatment plan [5] [6] in next step, then avoid the blindness of postoperative chemotherapy, improve the quality of life for patients. Because of its advantage in lowering the stage for primary tumor, NAC has become a standard treatment for patients with late-stage breast cancer [7] [8] [9].

Clinically, according to the expression of ER, PR, HER2 and Ki67, breast cancer is divided into: 1) Luminal type A; 2) Luminal type B; 3 ) HER-2 overexpression type; 4$)$ three-negative type [10]. It is well-known that ER and PR positive normally mean that patients are more sensitive to endocrine therapy. A retrospective analysis has reported that ER and PR in breast cancer predict patients' sensitivity to chemotherapy and can help assess prognosis [11] [12]. By studying thousands of patients with locally advanced breast cancer and lymph node metastasis, Berry found that ER-negative breast cancer patients benefited more from chemotherapy [13] than ER-positive breast cancer patients. Compared with ER-positive breast cancer, NSABP B27 clinical trials showed ER-negative breast cancer has a higher pCR (16.7\% vs. 6.8\%) [14]. Some clinical trials in China have reached the same conclusion [15] [16], and no different opinions have been reported in the literature. This study also concluded that hormone receptor-negative patients have better chemotherapy results, which may be because ER-negative tumors have better replication capacity than ER-positive tumors, so ER-negative tumors are more sensitive to chemotherapy than ER-positive tumors, and this sensitivity maybe also increases as tumor expansion increases. The overexpression of HER2 predicts that the tumor has a strong invasive ability, and the tumor has a high possibility of malignancy, it is prone to 
recurrence and has a poor prognosis [17]. There are few studies on the correlation between HER2 expression and chemotherapy efficacy, and most of these studies have no significant correlation between HER2 overexpression and chemotherapy case response rate [18]. In this study, the effective rate in the HER2 expression group was $58.8 \%$, and the effective rate in the non-overexpression group was $91.1 \%$. The difference between the two groups was statistically significant, indicating that HER2 overexpressing patients are more susceptible to drug resistance and less sensitive to chemotherapy. For patients with HER2-strong positives, the combination of the targeted therapy Herceptin and neoadjuvant chemotherapy can significantly improve the case remission rate of breast cancer, so the Herceptin shall be used for HER2-positive patients at the same time.

Whether Chemotherapy could change the expression status and level of these factors such as er, pr and HER2 or not, there is no unified conclusion till now. Previous studies have shown that NAC could change the status of hormone receptor [19]-[24] and HER2 [21] [23] [24] [25] [26], but some studies have reached the opposite conclusion [27] [28] [29] [30]. This study reminds that chemotherapy could change the status of hormone receptors and her2, but it is mainly about increase and decrease of expression, the qty of changing from positive to negative or changing from negative to positive is less, there is no statistical significance, and the change have no correlation with chemotherapy regimen Choose.

This study shows that hormone receptors and HER2-negative patients have better efficacy and benefit more from chemotherapy, so it could be used as an indicator to predict whether breast cancer is sensitive to neoadjuvant chemotherapy or not. The status of hormone receptors may be changed after neoadjuvant chemotherapy, but there is no statistically significant about that the change could affect the change of treatment. Patients with PCR obtained by neoadjuvant chemotherapy have significantly better DFS and OS than those without pCR, it means patients with $\mathrm{PCR}$ have a better prognosis, so the molecular typing of breast cancer and pCR could be as a independent prognostic factors for chemotherapy of breast cancer.

\section{Conflicts of Interest}

The author declares no conflicts of interest regarding the publication of this paper.

\section{References}

[1] Yuan, J.Q., Wang, S.M., Tang, L.L., et al. (2015) Relative Dose Intensity and Therapy Efficacy in Different Breast Cancer Molecular Subtypes: A Retrospective Study of Early Stage Breast Cancer Patients Treated with Neoadjuvant Chemotherapy. Breast Cancer Research and Treatment, 151, 405-413. https://doi.org/10.1007/s10549-015-3418-z

[2] DeSantis, C., Siegel, R., Bandi, P., et al. (2011) Breast Cancer Statistics, 2011. CA: A Cancer Journal for Clinicians, 61, 409-418. https://doi.org/10.3322/caac.20134 
[3] Saly, N.A., Temidayo, O. and Clement, A. (2010) Emerging Breast Cancer Epidemic: Evidence from Africa. Breast Cancer Research, 12, S8. https://doi.org/10.1186/bcr2737

[4] Cleator, S., Parton, M. and Dowsett, M. (2002) The Biology of Neoadjuvant Chemotherapy for Breast Cancer. Endocrine-Related Cancer, 9, 183-195.

[5] Ercanti, I.A., Mercanti, A., Fiorio, E., Mandarà, M., Giovannini, M., et al. (2005) Invasive-Breast Cancer: Ki-67 Evaluation in 3909 Early Breast Cancer Patients. Journal of Clinical Oncology, 23, 678. https://doi.org/10.1200/jco.2005.23.16 suppl.678

[6] Jiang, W., Yao, Y. and Wang, X. (2011) Effect of Neoadjuvant Chemotherapy on Breast Cancer and Its Judgment Method. Modern Medicine, 39, 237-340.

[7] Hortobagyi, G.N. (1990) Comprehensive Management of Locally Advanced Breast Cancer. Cancer, 66, 1387-1391. https://doi.org/10.1002/1097-0142(19900915)66:14+<1387::AID-CNCR2820661414 $>3.0 . \mathrm{CO} ; 2-\mathrm{I}$

[8] Schwartz, G.F. and Hortobagyi, G.N. (2004) Proceedings of the Consensus Conference on Neoadjuvant Chemotherapy in Carcinoma of the Breast, April 26-28, 2003, Philadelphia, Pennsylvania. Cancer, 100, 2512-2532. https://doi.org/10.1002/cncr.20298

[9] Mauri, D., Pavlidis, N. and Ioannidis, J.P.A. (2005) Neoadjuvant versus Adjuvant Systemic Treatment in Breast Cancer: A Meta-Analysis. Journal of the National Cancer Institute, 97, 188-194. https://doi.org/10.1093/jnci/dji021

[10] Goldhirch, A., Wood, W.C., et al. (2011) Strategies for Subtypes-Dealing with the Diversity of Breast Cancer: Highlights of the St. Gallen International Expert Consensus on the Primary Therapy of Early Breast Cancer 2011. Annals of Oncology, 22, 1736-1747. https://doi.org/10.1093/annonc/mdr304

[11] Ring, A.E., Smith, I.E., Ashley, S., et al. (2004) Oestrogen Receptor Status, Pathological Complete Response and Prognosis in Patients Receiving Neoadjuvant Chemotherapy for Early Breast Cancer. British Journal of Cancer, 91, 2012-2071. https://doi.org/10.1038/sj.bjc.6602235

[12] Kaufmann, M., Uon Minckwitz, G., Bear, H.D., et al. (2007) Recommendations from an International Expert Panel on the Use of Neoadjuvant (Primary) Systemic Treatment of Operable Breast Cancer: New Perspective 2006. Annals of Oncology, 18, 1927-1341. https://doi.org/10.1093/annonc/mdm201

[13] Berry, D.A., Cirrincone, C., Henderson, I.C., et al. (2006) Estrogen-Receptor Status and Outcomes of Modern Chemotherapy for Patients with Node-Positive Breast Cancer. JAMA, 295, 1658-1667. https://doi.org/10.1001/jama.295.20.2356-a

[14] Bear, H.D., Anderson, S., Brown, A., et al. (2003) The Effect on Tumor Response of Adding Sequential Preoperative Docetaxel to Preoperative Doxorubicin and Cyclophosphamide: Preliminary Results from National Surgical Adjuvant Breast and Bowel Project Protocol B-27. Journal of Clinical Oncology, 21, 4165-4174. https://doi.org/10.1200/JCO.2003.12.005

[15] Li, J., Ouyang, T., Wang, T., et al. (2004) Clinical Study of Neoadjuvant Chemotherapy for Primary Breast Cancer. Chinese Cancer Magazine, 26, 493-495.

[16] Liu, R., Lv, W., Wei, H., et al. (2008) Relationship between the Expression of Breast ER, PR, p53, Her-2 and the Efficiency of Neoadjuvant Chemotherapy. Chinese General Surgical Literature, 2, 117-120.

[17] Dagrda, G.P., Mezzlani, A., Alasio, L., et al. (2003) Her-2/Neu Assessment in Pri- 
mary Chemotherapy Treated Breast Carcinoma: No Evidence of Gene Profile Changing. Breast Cancer Research and Treatment 80, 207-214. https://doi.org/10.1023/A:1024579206250

[18] Barrett-Lee, P.J. (2005) Growth Factor Signalling in Clinical Breast Cancer and Its Impact on Response to Conventional Therapies: A Review of Chemotherapy. Endocrine-Related Cancer, 12, S125-S133. https://doi.org/10.1677/erc.1.01024

[19] Chen, S., Chen, C.M., Yu, K.D., Zhou, R.J. and Shao, Z.M. (2012) Prognostic Value of a Positive-to-Negative Change in Hormone Receptor Status after Neoadjuvant Chemotherapy in Patients with Hormone Receptor-Positive Breast Cancer. Annals of Surgical Oncology, 19, 3002-3011. https://doi.org/10.1245/s10434-012-2318-2

[20] Lee SH, Chung MA, Quddus MR, Steinhoff MM, Cady B. (2003) The Effect of Neoadjuvant Chemotherapy on Estrogen and Progesterone Receptor Expression and Hormone Receptor Status in Breast Cancer. The American Journal of Surgery, 186, 348-350. https://doi.org/10.1016/S0002-9610(03)00271-X

[21] Vande Ven, S, Smit, V.T., Dekker, T.J., Nortier, J.W. and Kroep, J.R. (2011) Discordances in ER, PR and HER2 Receptors after Neoadjuvant Chemotherapy in Breast Cancer. Cancer Treatment Reviews, 37, 422-430. https://doi.org/10.1016/j.ctrv.2010.11.006

[22] Zhang, N., Moran, M.S., Huo, Q., Haffty, B.G. and Yang, Q. (2011) The Hormonal Receptor Status in Breast Cancer Can Be Altered by Neoadjuvant Chemotherapy: A Meta-Analysis. Cancer Investigation, 29, 594-598. https://doi.org/10.3109/07357907.2011.621913

[23] Burcombe, R.J., Makris, A., Richman, P.I., Daley, F.M., Noble, S., Pittam, M., Wright, D., Allen, S.A., Dove, J. and Wilson, G.D. (2005) Evaluation of ER, PgR, HER-2 and Ki-67 as Predictors of Response to Neoadjuvant Anthracycline Chemotherapy for Operable Breast Cancer. British Journal of Cancer, 92, 147-155. https://doi.org/10.1038/sj.bjc.6602256

[24] Shet, T., Agrawal, A., Chinoy, R., Havaldar, R., Parmar, V. and Badwe, R. (2007) Changes in the Tumor Grade and Biological Markers in Locally Advanced Breast Cancer after Chemotherapy-Implications for a Pathologist. Breast, 13, 457-464. https://doi.org/10.1111/j.1524-4741.2007.00465.x

[25] Adams, A.L., Eltoum, I., Krontiras, H., Wang, W. and Chhieng, D.C. (2008) The Effect of Neoadjuvant Chemotherapy on Histologic Grade, Hormone Receptor Status, and HER2/Neu Status in Breast Carcinoma. The Breast Journal, 14, 141-146. https://doi.org/10.1111/j.1524-4741.2007.00544.x

[26] Quddus, R.M., Sung, J.C., Zhang, C., Pasqueriello, T., Eklund, M. and Steinhoff, M.M. (2005) HER-2/Neu Expression in Locally Advanced Breast Carcinomas: Preand Post-Neoadjuvant Chemotherapy. Breast Cancer, 12, 294-298. https://doi.org/10.2325/jbcs.12.294

[27] Penault-Llorca, F., Cayre, A., Bouchet Mishellany, F., Amat, S., Feillel, V., LeBouedec, G., Ferrière, J., DeLatour, M. and Chollet, P. (2003) Induction Chemotherapy for Breast Carcinoma: Predictive Markers and Relation with Outcome. International Journal of Oncology, 22, 1319-1325. https://doi.org/10.3892/ijo.22.6.1319

[28] Dowsett, M., Ebbs, S.R., Dixon, J.M., Skene, A., Griffih, C., Boeddinghaus, I., Salter, J., Detre, S., Hills, M., Ashley, S., Francis, S., Walsh, G. and Smith, I.E. (2005) Biomarker Changes during Neoadjuvant Anastrozole, Tamoxifen, or the Combination: Influence of Hormonal Status and HER-2 in Breast Cancer-A Study from the Impact Trialists. Journal of Clinical Oncology, 23, 2477-2492.

https://doi.org/10.1200/JCO.2005.07.559 
[29] Arens, N., Bley, L.U. and Hildenbrand, R. (2005) HER2/Neu, p53, Ki67, and Hormone Receptors Do Not Change during Neoadjuvant Chemotherapy in Breast Cancer. Virchows Archiv, 446, 489-496. https://doi.org/10.1007/s00428-005-1244-0

[30] Kasami, M., Uematsu, T., Honda, M., Yabuzaki, T., Sanuki, J., Uchida, Y. and Sugimura, H. (2008) Comparison of Estrogen Receptor, Progesterone Receptor and Her-2 Status in Breast Cancer Pre- and Post-Neoadjuvant Chemotherapy. Breast, 17, 523-527. https://doi.org/10.1016/j.breast.2008.04.002 